Old Dominion University

ODU Digital Commons

$1-1-2020$

Gabapentin Drug Misuse Signals: A Pharmacovigilance Assessment Using the FDA Adverse Event Reporting System

Rachel Vickers-Smith

Jiangwen Sun

Richard J. Charnigo

Michelle R. Lofwall

Sharon L. Walsh

See next page for additional authors

Follow this and additional works at: https://digitalcommons.odu.edu/computerscience_fac_pubs

Part of the Computer Sciences Commons, Psychiatry and Psychology Commons, and the Substance Abuse and Addiction Commons 


\section{Authors}

Rachel Vickers-Smith, Jiangwen Sun, Richard J. Charnigo, Michelle R. Lofwall, Sharon L. Walsh, and Jennifer R. Havens 
Full length article

\title{
Gabapentin drug misuse signals: A pharmacovigilance assessment using the FDA adverse event reporting system
}

\author{
Rachel Vickers-Smith ${ }^{\mathrm{a}, \mathrm{b}, \mathrm{c}, \mathrm{d}, *}$, Jiangwen Sun ${ }^{\mathrm{e}}$, Richard J. Charnigo ${ }^{\mathrm{b}}$, Michelle R. Lofwall ${ }^{\mathrm{d}}$, \\ Sharon L. Walsh ${ }^{\mathrm{d}, \mathrm{f}}$, Jennifer R.. Havens ${ }^{\mathrm{c}, \mathrm{d}}$ \\ ${ }^{a}$ University of Louisville School of Nursing, Louisville, KY 40202, USA \\ ${ }^{\mathrm{b}}$ Department of Biostatistics, University of Kentucky College of Public Health, 111 Washington Avenue, Lexington, KY 40536, USA \\ ${ }^{\mathrm{c}}$ Department of Epidemiology, University of Kentucky College of Public Health, 111 Washington Avenue, Lexington, KY 40536, USA \\ ${ }^{\mathrm{d}}$ Center on Drug and Alcohol Research, Department of Behavioral Science, University of Kentucky College of Medicine, 845 Angliana Avenue, Lexington, KY 40508, USA \\ ${ }^{\mathrm{e}}$ Department of Computer Science, Old Dominion University, Norfolk, VA 23529, USA \\ f Department of Pharmaceutical Sciences, University of Kentucky College of Pharmacy, 789 South Limestone, Lexington, KY 40508, USA
}

\section{A R T I C L E I N F O}

\section{Keywords:}

Gabapentin

Pregabalin

Duloxetine

Pharmacovigilance

Adverse events

Misuse

\begin{abstract}
A B S T R A C T
Background: Although there have been increasing reports of intentional gabapentin misuse, epidemiological evidence for the phenomenon is limited. The purpose of this study was to determine whether there are pharmacovigilance abuse signals for gabapentin.

Methods: Using FDA Adverse Events Reporting System reports from January 1, 2005 to December 31, 2015, we calculated pharmacovigilance signal measures (i.e., reporting odds ratio, proportional reporting ratio, information component, and empirical Bayes geometric mean) for abuse-related adverse event (AR-AE)-gabapentin pairs. Loglinear modeling assessed the frequency of concurrent reporting of abuse-related and abusespecific AEs (AS-AEs) associated with gabapentin. Findings were compared to a positive (pregabalin) and negative (duloxetine) control.

Results: From 2005-2015 there were 5,951,229 unique AE reports submitted to the FDA including 99,977 for gabapentin, 73,977 for duloxetine, and 97,813 for pregabalin. Significant drug-AR-AE pair signals involving gabapentin included: drug abuser, multiple drug overdose, and substance-induced psychotic disorder. Significant drug AR-AE signals involving gabapentin and pregabalin, but not duloxetine, were: ataxia, dependence, drug abuse, increased drug tolerance, and overdose. Compared to duloxetine, gabapentin had significantly greater odds of a coreport for an AS-AE with drug withdrawal syndrome (OR: 6.55), auditory hallucinations (OR: 4.57), delusions (OR: 2.36), euphoric mood (OR: 5.45), ataxia (OR: 2.85), drug abuser (OR: 3.01), aggression (OR: 1.98), psychotic disorder (OR: 1.96), and feeling abnormal (OR: 1.31).

Conclusions: We identified abuse-related signals for gabapentin and highlighted several CNS effects that may be associated with its abuse. Gabapentin prescribers should be aware of the drug's abuse liability and effects that may accompany its use.
\end{abstract}

\section{Introduction}

Gabapentin is approved by the U.S. Food and Drug Administration (FDA) for post-herpetic neuralgia and as an anti-epileptic, but is frequently used off-label for non-herpetic pain, mood disorders, and as a treatment for alcohol withdrawal and alcohol use disorder. In the latest guidance report for pain treatment, the Centers for Disease Control and Prevention (CDC) identified gabapentin as a first-line medication for treating chronic pain (Dowell et al., 2016). Since its market release in 1993, gabapentin was presumed to have no abuse potential, which has likely led to its extensive off-label prescribing (it is estimated that between $83-95 \%$ of all gabapentin prescriptions are for a non-approved

\footnotetext{
Abbreviations: AE, adverse event; AER, adverse event report; AR-AE, abuse related adverse event; AS-AE, abuse specific adverse event; C, concomitant drug; CDC,

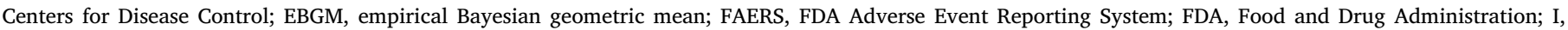

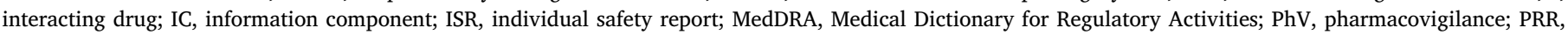
proportional reporting ratio; PS, primary suspect drug; PT, preferred term; ROR, reporting odds ratio; SS, secondary suspect drug

* Corresponding author at: University of Louisville, School of Nursing, 555 South Floyd Street, Louisville, KY 40202, USA.

E-mail addresses: rachelannvickers@gmail.com, rachel.vickers@louisville.edu (R. Vickers-Smith).
} 
use; Hamer et al., 2002; Radley et al., 2006). However, since the first published report of gabapentin misuse in 1994 (Fischer et al., 1994), a substantial number of accounts of gabapentin misuse and abuse have followed. A recent systematic review identified 23 published case studies and epidemiologic reports of gabapentin misuse/abuse from seven different countries (Smith et al., 2016).

Evidence on the prevalence of gabapentin misuse (i.e., use in a manner or for a purpose other than indicated) (World Health Organization, 2015a) is limited. One study estimated the population prevalence of gabapentin misuse at $1 \%$ in the United Kingdom (Kapil et al., 2014). However, three studies estimated the prevalence of gabapentin misuse within substance misuse samples in the United States and the United Kingdom to be between 15-22\% (Baird et al., 2014; Smith et al., 2015; Wilens et al., 2015). The mechanism by which gabapentin produces analgesic and anticonvulsant effects is unknown, though it is likely due to an interaction with calcium channels to reduce neurotransmitter release from neurons in the central nervous system (Bockbrader et al., 2010). There is a wide spectrum of subjective effects of gabapentin, particularly when it is not used as intended (e.g., in larger doses than prescribed), including: dissociation, euphoria, sedation/relaxation/calmness, elevated mood, disinhibition, delirium, feeling "high," and feeling drunk (Reeves and Burke, 2014; Reeves and Ladner, 2014; Satish et al., 2015; Schifano et al., 2011; Vickers Smith et al., 2018).

Without controlled pharmacological studies to assess gabapentin's abuse potential, other available data can be used to estimate the risk of gabapentin misuse. One such resource is the FDA Adverse Event Reporting System (FAERS), a publicly available, FDA- maintained database in the United States. FAERS is a passive surveillance program to which post-marketing adverse events (AEs) associated with any drug or biologic product can be reported. Approximately $5 \%$ of AEs reported to FAERS are generated voluntarily by health professionals (e.g., physicians, pharmacists, nurses) and consumers (e.g., patients, family members, lawyers), who can submit AEs via the online submission system called MedWatch (U.S. Food and Drug Administration, 2016). The other $95 \%$ of FAERS reports come from voluntary AE reporting to the drug sponsor or manufacturer, which is then required to forward the report to the FDA (U.S. Food and Drug Administration, 2016). The Center for Drug Evaluation and Research, a division of the FDA, monitors reports and further evaluates concerns identified through FAERS (Center for Drug Evaluation and Research, 2018a). If there is a safety concern over a drug or device, the FDA can choose to take regulatory action, including, but not limited to: updating labeling information, restricting use, communicating safety information to the public, or product removal from the market (Center for Drug Evaluation and Research, 2018a). As of 2016, FAERS has received over 12 million reports, two million of which were from 2016 alone (U.S. Food and Drug Administration, 2016).

Pharmacovigilance (PhV), which is the collection, study, detection, and prevention of drug adverse events, is a useful tool for hypothesis generation or hypothesis testing of drug-AE pairs, though a theoretical conceptualization of the drug-AE combination one intends to investigate is prerequisite (Poluzzi et al., 2012). PhV studies typically use several assessment measures to detect a "signal" for a particular drug (World Health Organization, 2015b), which is a previously unknown possible causal association of an adverse event resulting from taking a drug (World Health Organization, 2012). Signals are disproportionality measures based on a $2 \times 2$ contingency table and determine whether a drug-AE pair occurs more often than expected by comparing signal values to published thresholds (Bate et al., 1998; Evans et al., 2001; Szarfman et al., 2002; van Puijenbroek et al., 2002).

We used the FAERS database to calculate signal measures for reports of gabapentin and abuse-related AEs (AR-AEs) and compared these findings to a negative and positive control. The AR-AEs of interest were selected $a$ priori based on effects associated with gabapentin misuse reflected in the current literature (Schifano et al., 2011; Smith et al.,
2016). Signals of misuse/abuse/addiction may not always be identified through observation of a single $\mathrm{AE}$ at a time (e.g., a report of gabapentin and ataxia does not necessarily indicate abuse); rather, it may be more useful to examine the joint occurrence of several AEs that are indicative of drug misuse/abuse/addiction. Therefore, in addition to the traditional signal measures, we used loglinear modeling to assess the frequency of concurrent reporting of AEs associated with gabapentin misuse/abuse.

\section{Material and methods}

\subsection{Data source}

All FAERS quarterly data from January 1, 2004 to December 31, 2015 were downloaded from the FDA website (Center for Drug Evaluation and Research, 2018b). However, because pregabalin was not approved by the FDA until December 30, 2004 (U.S. Food and Drug Administration, 2005), data from 2004 were excluded. Each quarterly data set contained 7 data files: (1) patient demographic and administrative information; (2) drug/biologic information for all medications reported for the event; (3) all Medical Dictionary for Regulatory Activities (MedDRA) terms coded for the adverse event; (4) patient outcomes for the $\mathrm{AE}$; (5) report sources for the $\mathrm{AE}$; (6) drug therapy start and end dates for the reported drug(s); and (7) all MedDRA terms for the reported drug's indications/diagnoses. For the purposes of this analysis, only the demographic, drug, and reaction data tables were used.

We used positive and negative controls with which to compare the gabapentin findings. Pregabalin, a structural analog of gabapentin with a similar mechanism of action, has been classified as a Schedule V drug because of its abuse potential, which made it an ideal candidate for the positive control. Because duloxetine, a serotonin-norepinephrine reuptake inhibitor, has been recommended as a first-line medication for the treatment of neuropathic pain (Dowell et al., 2016) (similar to gabapentin) but is not a controlled substance and generally has produced no signal of abuse liability, it was selected as the negative control.

Based on the proposed methodology of Moore et al. (1997) a case/ non-case approach was used, where each drug-AE pair of interest denoted a case and all other possible pairs were non-cases. In every FAERS $\mathrm{AE}$ drug file, FDA clinical reviewers assigned role codes to each reported drug and indicated as follows: primary suspect drug (PS), secondary suspect drug (SS), interacting (I), or concomitant (C). Often, only PS, SS, and I medications are considered as cases. However, others have raised concerns about excluding concomitant medications from among cases, particularly if they are associated with an unexpected drug-AE association. As explained in the EudraVigilance data analysis guidelines, “...it is quite often the case that drug-event associations are not commonly established until knowledge of the potential signal [is] available" (European Medicines Agency, 2006). Therefore, due to the historic opinion that gabapentin had no abuse liability it was apt to include cases where gabapentin was listed as a concomitant medication. For consistency, cases where pregabalin or duloxetine were listed as concomitant medications were also included.

\subsection{Case identification - drugs}

Drug cases (i.e., AE reports [AERs] that included gabapentin, pregabalin, and/or duloxetine) were identified in the FAERS drug table using a phonetic algorithm via the soundex function in the $\mathrm{R}$ package, phonics (Howard, 2018). The soundex function was employed to identify potential drug case matches by both the brand and generic names of the case drugs. This procedure works through phonetic matching and can help to reduce the effect of variations in spelling. The second author manually scanned potential matches identified through the phonetic algorithm to determine whether they were true cases. All analyses were conducted in $\mathrm{R}$. 


\subsection{Data cleaning}

Each AER in FAERS has a unique "ISR (individual safety report) number," which can be used to link files across all seven data tables. A case number also identifies an AER; however, it may encompass several ISR numbers (AERs) due to follow-up reporting for the same event. Once the drug files were merged with their corresponding demographic files by ISR number, we retained the AER in each Case ID series with the most recent date, according to the FAERS cleaning protocol (Banda et al., 2016), and duplicates were removed. The demographic/drug file was then merged with the MedDRA AE file by the ISR number.

\subsection{Case identification - AEs}

Using several sources (Schwan et al., 2010; Smith et al., 2013), we created a list of MedDRA preferred terms (PT) that were explicit indications of abuse (e.g., drug diversion, drug addiction) and those that could be indicative of abuse (e.g., ataxia, falls, euphoric mood, dissociation). Here abuse-related (AR-AE) will be used to incorporate both explicit abuse MedDRA terms and MedDRA terms that are possible indicators of abuse, while abuse-specific (AS-AE) refers to explicit abuse terms only. The list was reviewed by a pharmacology expert [SLW] and a psychiatrist [MRL] and revised until a final list was agreed upon (see Appendix 1). It should be noted that each AER could, and most often did, include more than one MedDRA term.

\subsection{Signal calculation}

Because AE reporting can be affected by many external factors, cumulative signal measures were calculated (Poluzzi et al., 2012); that is, data were aggregated over the 11-year study period rather than calculated quarterly. Descriptive statistics were calculated for each drug-AR-AE pair. Traditional signal measures include the proportional reporting ratio (PRR)(Evans et al., 2001), reporting odds ratio (ROR) (van Puijenbroek et al., 2002), the information component (IC)(Bate et al., 1998), and the empirical Bayesian geometric mean (EBGM) (Szarfman et al., 2002). Published criteria for each signal measure are as follows (Poluzzi et al., 2012):

For $\mathrm{N}_{\mathrm{D}}$, which is the number of AERs for any given drug:

PRR: $N_{D} \geq 3$, PRR $\geq 2, \chi^{2} \geq 4$;

ROR: lower limit of $95 \%$ confidence interval $>1$;

IC: lower limit of two-sided $95 \%$ credible interval $>0$;

EBGM: $\mathrm{N}_{\mathrm{D}}>0$, lower limit of one-sided $95 \%$ credible interval $>2$.

First, a composite AR-AE variable was created, that is, any AER that reported at least one of the AR-AEs was coded as 1 and AERs that did not report any of these AR-AEs were coded as 0 . Signal measures were calculated for each drug-composite AR-AE pair. Then signal measures were calculated for individual AR-AE-drug pairs. Because the traditional signal measures differ in their sensitivity and specificity, we decided that for our purposes, a drug-AE pair would be significant if all four signal measures met the thresholds described above. The $\mathrm{R}$ package, PhViD (Ahmed and Poncet, 2016), was used to obtain all signal scores.

\subsection{Loglinear analysis}

Loglinear models allow for the simultaneous examination of the association between more than two categorical variables, essentially an extension of the $2 \times 2$ contingency table to a $2 \times 2 \times \ldots \times 2$ table, particularly useful when there is more than one response variable. This type of model can describe the joint distribution of any number of categorical factors.

First, a composite abuse-specific (AS-AE) variable was created where any AER that reported at least one AS-AE was coded as 1 and AERs that did not were coded as 0. The AS-AEs included: addiction, dependence, drug abuse, drug dependence, drug diversion, intentional (drug) misuse, intentional overdose, multiple drug overdose, overdose, prescription drug use without a prescription, substance abuse, and substance use. MedDRA terms drug abuser and substance abuser were not included as AS-AEs because those refer to the social circumstances surrounding the event. Therefore, information may be provided in the AER that the individual had a history of drug misuse, but that does not necessarily indicate that abuse occurred.

Next, loglinear modeling was used to evaluate the association between the co-occurrence of an AS-AE and each AE that was a possible indicator of abuse (e.g., ataxia, substance abuser) in AERs for gabapentin and pregabalin, with duloxetine as the referent group. All data were assumed to have come from Poisson distributions. Further, AERs that co-indicated any of the case drugs together (e.g., AER with gabapentin and pregabalin; AER with pregabalin and duloxetine) were not included in the loglinear analysis to reduce potential conflation of effects.

\section{Results}

From 2005-2015 there were 5,951,229 unique AERs submitted to the FDA. Of those, 99,977 included gabapentin, 73,977 included duloxetine, and 97,813 included pregabalin. Overall, the general trends for received AERs for each case drug were increasing, perhaps more clearly so for pregabalin and gabapentin than for duloxetine (Fig. 1). Interestingly, AERs for gabapentin, pregabalin, and duloxetine shared many of the same most frequently reported AEs including drug ineffectiveness, pain, nausea, fatigue and dizziness (Table 1).

Nearly one-quarter of all gabapentin reports involved at least one abuse-related AE (22.93\%; Table 2). That percentage was slightly higher for pregabalin and duloxetine (26.13 and $29.32 \%$, respectively). Of all the gabapentin-abuse-related AEs, dizziness was reported most frequently (5.25\%), followed by falls ( $4.48 \%$ ), and somnolence (3.33 $\%$ ). Dizziness and somnolence were also the most frequently reported abuse-related AEs reported for pregabalin $(6.59 \%$ and $5.17 \%$, respectively), while dizziness ( $8.03 \%)$, drug withdrawal syndrome $(6.42$ $\%$ ), and feeling abnormal (5.26 \%) were most common for duloxetine. With regard to AS-AEs, overdose was reported most frequently for all three drugs (gabapentin: $1.37 \%$; pregabalin: $0.94 \%$; duloxetine: 1.05 $\%)$. Also in the top five most commonly reported AS-AEs for all three drugs were: drug abuse (gabapentin: $0.57 \%$; pregabalin: $0.66 \%$; duloxetine: $0.37 \%$ ), intentional drug misuse (gabapentin: $0.55 \%$; pregabalin: $0.55 \%$; duloxetine: $0.58 \%$ ), intentional overdose (gabapentin: $0.50 \%$; pregabalin: $0.36 \%$; duloxetine: $0.51 \%$ ), and drug dependence (gabapentin: $0.49 \%$; pregabalin: $0.59 \%$; duloxetine: $0.29 \%$ ).

When examining signal measures of gabapentin, 30 gabapentin-AE pairs met published threshold criteria for all four measures (Appendix 2). Likewise, 32 pregabalin-AE pairs and 29 duloxetine-AE pairs met published signal threshold criteria for all four measures. Significant signals (i.e., using our more stringent definition) common to all three drugs included aggression, confusional state, disorientation, dizziness, drug dependence, drug tolerance, drug withdrawal syndrome, euphoric mood, fall, feeling abnormal, feeling drunk, gait disturbance, hallucination, visual hallucination, incoherent, intentional drug misuse, intentional overdose, mood altered, off-label use, somnolence, and thinking abnormal. Significant AE signals unique to gabapentin (i.e., not all 4 signals were significant for pregabalin or duloxetine) were: drug abuser, multiple drug overdose, and substance-induced psychotic disorder. Significant AE signals with gabapentin and pregabalin, but not duloxetine (i.e., not all 4 signals were significant for duloxetine), were: ataxia, dependence, drug abuse, drug tolerance increased, and overdose. Only delusion produced a significant AE signal with gabapentin and duloxetine, but not pregabalin. Gabapentin, pregabalin, and duloxetine produced significant signals for both the composite abuse-related $\mathrm{AE}$ variable and the abuse-specific AE variable. Each drug had ASAEs that met the significance threshold for one or more of the PhV measures, but not for all 4. These included: dependence (duloxetine), 


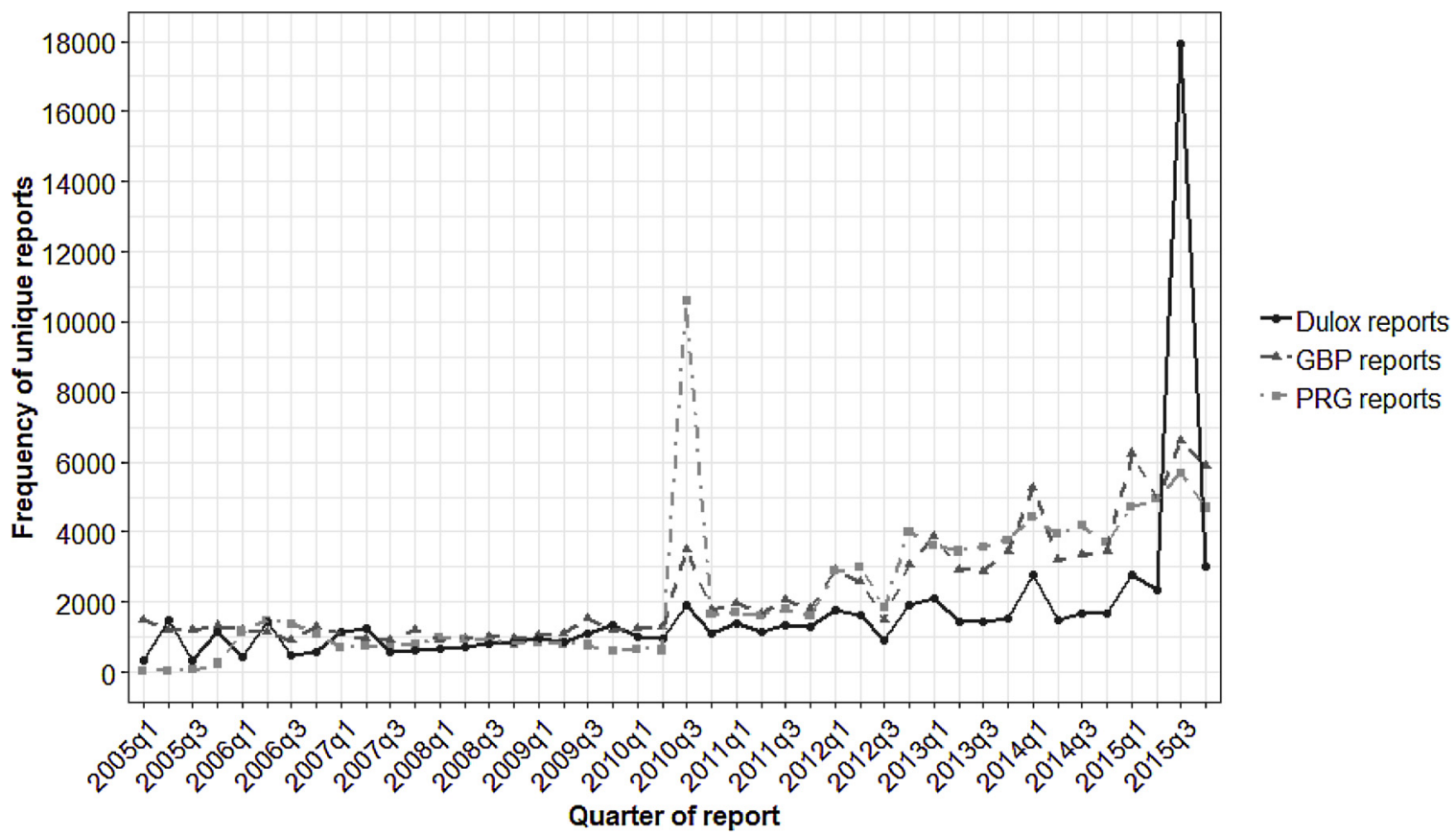

Fig. 1. Adverse reporting trends by quarter, 2005-2015.

Dulox = duloxetine; GBP = gabapentin; PRG = pregabalin

Table 1

Highest frequency of adverse events by drug, 2005-2015.

\begin{tabular}{lll}
\hline Gabapentin (n) & Pregabalin (n) & Duloxetine (n) \\
\hline Drug ineffective (9913) & Pain (9962) & Nausea (7354) \\
Pain (6784) & Drug ineffective (9290) & Dizziness (5941) \\
Nausea (6341) & Dizziness (6444) & Headache (5069) \\
Fatigue (5690) & Weight increased & Drug ineffective (5016) \\
& (5764) & \\
Dizziness (5251) & Somnolence (5059) & Fatigue (4825) \\
Headache (4838) & Nausea (4304) & Drug withdrawal syndrome \\
& & (4752) \\
Fall (4479) & Malaise (4128) & Pain (4747) \\
Diarrhea (4408) & Pain in extremity & Insomnia (4132) \\
& (4055) & \\
Dyspnea (4266) & Fatigue (3996) & Depression (4108) \\
Depression (3935) & Feeling abnormal & Feeling abnormal (3889) \\
& (3952) & \\
\hline
\end{tabular}

drug abuse (duloxetine), drug diversion (gabapentin and pregabalin), multiple drug overdose (pregabalin and duloxetine), overdose (duloxetine), substance abuse (gabapentin, pregabalin, and duloxetine), and substance use (gabapentin, pregabalin, and duloxetine).

Approximately $12-19 \%$ of all AERs for each drug contained one or more of the other case drug(s). When the number of reports was reduced to exclude overlap between gabapentin, pregabalin, and/or duloxetine, the numbers of unique abuse-related reports for each drug were 3435 for gabapentin, 2906 for pregabalin, and 2052 for duloxetine. For gabapentin, somnolence, drug withdrawal syndrome, and confusional state were most often co-reported with an AS-AE (Table 3). Somnolence was also the most often co-reported with a pregabalin AS$\mathrm{AE}$, while drug withdrawal syndrome had the highest co-reporting with a duloxetine AS-AE.

Based on results from the loglinear models, compared to the negative control, duloxetine, gabapentin had over six times the odds of a coreport of drug abuse (as an AS-AE) and drug withdrawal syndrome; pregabalin also had increased odds of this simultaneous report compared to duloxetine, though it was not as high as for gabapentin (Table 4). Gabapentin and pregabalin also had significantly greater odds of a co-report for an AS-AE with auditory hallucinations (OR: 4.57 and 4.28, respectively), euphoric mood (OR: 5.45 and 2.47, respectively), delusion (OR: 2.36 and 3.33, respectively), and aggression (OR: 1.98 and 2.47, respectively) compared to duloxetine. Interestingly, an abuse-specific event and drug abuser were reported together with significantly increased odds for gabapentin compared to duloxetine, but pregabalin did not have significantly increased odds. This occurred with co-reports of ataxia, psychotic disorder, and feeling abnormal, as well.

\section{Discussion}

This study is the first post-market pharmacovigilance study to examine gabapentin reporting in the FDA Adverse Event Reporting System and compare findings with those of a negative and a positive control. Though gabapentin, pregabalin, and duloxetine reports all produced signals for any abuse-related and abuse-specific adverse events, important differences appeared when evaluating the signals individually. Specifically, both gabapentin and pregabalin produced significant signals for ataxia, dependence, drug abuse, increased drug tolerance, and overdose. This is not surprising given that gabapentin and pregabalin have similar mechanisms of action.

Another novel aspect of the current study is that we evaluated AERs where drug abuse was indicated and assessed which effects were most often co-reported with abuse. Drug withdrawal syndrome, euphoric mood, auditory hallucinations, delusions, and aggression were more often endorsed in combination with drug abuse for gabapentin or pregabalin than for the negative control, duloxetine. While it is not necessarily remarkable that such effects have been reported for gabapentin and pregabalin (in fact several of these AEs are listed on the drugs' labels), what is particularly notable is that they were reported as occurring with drug abuse, which gives insight into the psychoactive effects that may be sought through misuse of these drugs. In a study by Schifano and colleagues (2011), data were accumulated from online anecdotes of recreational misuse of gabapentinoids and their results are concordant with those identified in this study (Schifano et al., 2011). Though pregabalin has been recognized as having abuse liability by the U.S. Drug Enforcement Administration (U.S. Department of Justice Drug Enforcement Administration Diversion Control Division, 2005) 
Table 2

Frequency of abuse-related adverse event reports by case drug.2005-2015

\begin{tabular}{|c|c|c|c|}
\hline Preferred term & $\begin{array}{l}\text { Gabapentin } \\
(\mathrm{n}=99,977) \\
\mathrm{n}(\%)\end{array}$ & $\begin{array}{l}\text { Pregabalin } \\
(\mathrm{n}=97,813) \\
\mathrm{n}(\%)\end{array}$ & $\begin{array}{l}\text { Duloxetine } \\
(\mathrm{n}=73,977) \\
\mathrm{n}(\%)\end{array}$ \\
\hline Dizziness & $5251(5.25)$ & 6444 (6.59) & $5941(8.03)$ \\
\hline Fall & $4479(4.48)$ & 3599 (3.68) & $2665(3.60)$ \\
\hline Somnolence & $3326(3.33)$ & $5059(5.17)$ & $2379(3.22)$ \\
\hline Feeling abnormal & $2859(2.86)$ & $3952(4.04)$ & $3889(5.26)$ \\
\hline Gait disturbance & $2637(2.64)$ & $2934(3.00)$ & $1403(1.90)$ \\
\hline Confusional state & $2476(2.48)$ & $2322(2.37)$ & $1838(2.48)$ \\
\hline Off-label use & $2260(2.26)$ & $1870(1.91)$ & $2966(4.01)$ \\
\hline Overdose* & $1374(1.37)$ & $918(0.94)$ & $777(1.05)$ \\
\hline Hallucination & $958(0.96)$ & $886(0.91)$ & $790(1.07)$ \\
\hline Drug withdrawal syndrome & $952(0.95)$ & $1495(1.53)$ & $4752(6.42)$ \\
\hline Disorientation & $740(0.74)$ & $723(0.74)$ & $567(0.77)$ \\
\hline Drug abuse* & $572(0.57)$ & $644(0.66)$ & $275(0.37)$ \\
\hline Aggression & $570(0.57)$ & $501(0.51)$ & $706(0.95)$ \\
\hline Thinking abnormal & $556(0.56)$ & $558(0.57)$ & $565(0.76)$ \\
\hline Intentional (drug) misuse* & $551(0.55)$ & $540(0.55)$ & $427(0.58)$ \\
\hline Intentional overdose* & $495(0.50)$ & $351(0.36)$ & $374(0.51)$ \\
\hline Drug dependence* & $490(0.49)$ & $579(0.59)$ & $217(0.29)$ \\
\hline Delirium & $404(0.40)$ & $355(0.36)$ & $244(0.33)$ \\
\hline Psychotic disorder & $331(0.33)$ & $265(0.27)$ & $340(0.46)$ \\
\hline Mood altered & $302(0.30)$ & $328(0.34)$ & $356(0.48)$ \\
\hline Hallucination, visual & $282(0.28)$ & $255(0.26)$ & $200(0.27)$ \\
\hline Ataxia & $249(0.25)$ & $224(0.23)$ & $100(0.14)$ \\
\hline Feeling drunk & $230(0.23)$ & $587(0.60)$ & $168(0.23)$ \\
\hline Euphoric mood & $185(0.19)$ & $538(0.55)$ & $151(0.20)$ \\
\hline Delusion & $174(0.17)$ & $106(0.11)$ & $158(0.21)$ \\
\hline Hallucination, auditory & $150(0.15)$ & $135(0.14)$ & $191(0.26)$ \\
\hline Incoherent & $146(0.15)$ & $110(0.11)$ & $79(0.11)$ \\
\hline Multiple drug overdose* & $146(0.15)$ & $39(0.04)$ & $49(0.07)$ \\
\hline Drug abuser & $106(0.11)$ & $26(0.03)$ & $29(0.04)$ \\
\hline Drug tolerance & $86(0.09)$ & $101(0.10)$ & $44(0.06)$ \\
\hline Dependence* & $84(0.08)$ & $63(0.06)$ & $38(0.05)$ \\
\hline Substance abuse* & $71(0.07)$ & $23(0.02)$ & $21(0.03)$ \\
\hline Dissociation & $43(0.04)$ & $80(0.08)$ & $99(0.13)$ \\
\hline Hallucinations, mixed & $43(0.04)$ & $55(0.06)$ & $46(0.06)$ \\
\hline Acute psychosis & $28(0.03)$ & $11(0.01)$ & $20(0.03)$ \\
\hline $\begin{array}{l}\text { Substance-induced psychotic } \\
\text { disorder }\end{array}$ & $26(0.03)$ & $10(0.01)$ & $11(0.01)$ \\
\hline Drug tolerance increased & $17(0.02)$ & $18(0.02)$ & $8(0.01)$ \\
\hline Drug diversion* & $10(0.01)$ & $9(0.01)$ & $25(0.03)$ \\
\hline Feeling of relaxation & $8(0.01)$ & $26(0.03)$ & $18(0.02)$ \\
\hline Elevated mood & $6(0.01)$ & $18(0.02)$ & $17(0.02)$ \\
\hline Substance use* & $5(0.01)$ & $5(0.01)$ & $1(0.00)$ \\
\hline Substance abuser & $2(0.00)$ & $0(0.00)$ & $0(0.00)$ \\
\hline Rebound psychosis & $1(0.00)$ & $0(0.00)$ & $0(0.00)$ \\
\hline Addiction* & $0(0.00)$ & $0(0.00)$ & $0(0.00)$ \\
\hline Drug addict & $0(0.00)$ & $0(0.00)$ & $0(0.00)$ \\
\hline Intoxication & $0(0.00)$ & $0(0.00)$ & $0(0.00)$ \\
\hline $\begin{array}{l}\text { Prescription drug use } \\
\text { without a prescription* }\end{array}$ & $0(0.00)$ & $0(0.00)$ & $0(0.00)$ \\
\hline Transient psychosis & $0(0.00)$ & $1(0.00)$ & $1(0.00)$ \\
\hline Any AR-AE & $22,929(22.93)$ & $25,554(26.13)$ & $21,689(29.32)$ \\
\hline
\end{tabular}

AR-AE: abuse-related adverse event. Note: Percentages are out of the total for each case drug. *Denotes an abuse-specific adverse event.

and the European Monitoring Centre for Drugs and Drug Addiction (EMCDDA)-Europol (European Monitoring Centre for Drugs and Drug Addiction, 2012), gabapentin is still assumed by the greater prescribing community to have no abuse potential. However, the similarities between gabapentin and pregabalin in reported effects in combination with drug abuse underscore the necessity of reevaluating the abuse liability of gabapentin.

Interestingly, drug abuse was co-reported with ataxia with significantly higher odds for gabapentin than duloxetine, but the effect was not observed with pregabalin. Ataxia is a common experience of alcohol intoxication (Diener et al., 1983; Roehrs and Roth, 2001); gabapentin has produced similar effects in the human laboratory (Bisaga and Evans, 2006) and, in a study by Peterson (2009), it was identified in 137 driving impairment cases in the State of Washington. Studies to
Table 3

Frequency of co-reporting of an abuse-specific adverse event by case drug and non-specific-abuse-related adverse event, 2005-2015.

\begin{tabular}{|c|c|c|c|}
\hline Preferred term & $\begin{array}{l}\text { Gabapentin } \\
(\mathrm{n}=3435) \\
\mathrm{n}(\%)\end{array}$ & $\begin{array}{l}\text { Pregabalin } \\
(\mathrm{n}=2906) \\
\mathrm{n}(\%)\end{array}$ & $\begin{array}{l}\text { Duloxetine } \\
(\mathrm{n}=2052) \\
\mathrm{n}(\%)\end{array}$ \\
\hline Somnolence & $262(7.6)$ & $269(9.3)$ & $130(6.3)$ \\
\hline Drug withdrawal syndrome & $215(6.3)$ & $163(5.6)$ & $172(8.4)$ \\
\hline Confusional state & $200(5.8)$ & $118(4.1)$ & $104(5.1)$ \\
\hline Fall & $187(5.4)$ & $128(4.4)$ & $97(4.7)$ \\
\hline Dizziness & $175(5.1)$ & $170(5.8)$ & $140(6.8)$ \\
\hline Feeling abnormal & $144(4.2)$ & 171(5.9) & $126(6.1)$ \\
\hline Off-label use & $99(2.9)$ & $110(3.8)$ & $114(5.6)$ \\
\hline Gait disturbance & $86(2.5)$ & $96(3.3)$ & $51(2.5)$ \\
\hline Aggression & $82(2.4)$ & $78(2.7)$ & $46(2.2)$ \\
\hline Hallucination & $75(2.2)$ & $53(1.8)$ & $48(2.3)$ \\
\hline Drug abuser & $62(1.8)$ & $13(0.4)$ & $8(0.4)$ \\
\hline Delirium & $58(1.7)$ & $25(0.9)$ & $24(1.2)$ \\
\hline Euphoric mood & $54(1.6)$ & $77(2.6)$ & $9(0.4)$ \\
\hline Thinking abnormal & $52(1.5)$ & $32(1.1)$ & $29(1.4)$ \\
\hline Disorientation & $46(1.3)$ & $37(1.3)$ & $29(1.4)$ \\
\hline Ataxia & $45(1.3)$ & $19(0.7)$ & $6(0.3)$ \\
\hline Psychotic disorder & $43(1.3)$ & $13(0.4)$ & $20(1.0)$ \\
\hline Drug tolerance & $29(0.8)$ & $28(1.0)$ & $7(0.3)$ \\
\hline Delusion & $26(0.8)$ & $19(0.7)$ & $9(0.4)$ \\
\hline Mood altered & $26(0.8)$ & $27(0.9)$ & $19(0.9)$ \\
\hline Hallucination, auditory & $20(0.6)$ & $15(0.5)$ & $5(0.2)$ \\
\hline Hallucination, visual & $16(0.5)$ & $14(0.5)$ & $8(0.4)$ \\
\hline Incoherent & $16(0.5)$ & $6(0.2)$ & $8(0.4)$ \\
\hline Feeling drunk & $10(0.3)$ & $18(0.6)$ & $3(0.1)$ \\
\hline Drug tolerance increased & $9(0.3)$ & $5(0.2)$ & $3(0.1)$ \\
\hline Hallucinations, mixed & $4(0.1)$ & $10(0.3)$ & $3(0.1)$ \\
\hline Feeling of relaxation & $1(0.0)$ & $5(0.2)$ & $1(0.0)$ \\
\hline Substance-induced psychotic disorder & $1(0.0)$ & $1(0.0)$ & $0(0.0)$ \\
\hline Substance abuser & $1(0.0)$ & $0(0.0)$ & $0(0.0)$ \\
\hline Dissociation & $0(0.0)$ & $1(0.0)$ & $3(0.1)$ \\
\hline Drug addict & $0(0.0)$ & $0(0.0)$ & $0(0.0)$ \\
\hline Elevated mood & $0(0.0)$ & $3(0.1)$ & $1(0.0)$ \\
\hline Intoxication & $0(0.0)$ & $0(0.0)$ & $0(0.0)$ \\
\hline Acute psychosis & $0(0.0)$ & $0(0.0)$ & $1(0.0)$ \\
\hline Rebound psychosis & $0(0.0)$ & $0(0.0)$ & $0(0.0)$ \\
\hline Transient psychosis & $0(0.0)$ & $0(0.0)$ & $0(0.0)$ \\
\hline
\end{tabular}

Note: Frequencies and percentages exclude any cases where case drugs were coreported.

examine how gabapentin misuse may impact psychomotor effects are warranted.

Gabapentin abuse signals were identified using national AE reporting data from the United States. However, this is not just an American phenomenon. Our recent review (Smith et al., 2016) noted that gabapentin misuse reports have also come from the United Kingdom, Germany, Finland, India, South Africa, and France. Further, in a recent paper by Chiappini and Schifano (2016) similar methods to those used in the present study were used to examine gabapentinoid misuse in the European Medicines Agency Suspected Adverse Drug Reactions database. The authors determined that nearly $5 \%$ of misuse/ abuse/dependence spontaneous $\mathrm{AE}$ reports were associated with gabapentin (Chiappini and Schifano, 2016). Evaluation of the Canadian Vigilance Adverse Drug Reaction Online Database also demonstrated gabapentin misuse (Zhang and Sproule, 2015).

Though not the focus of this study, it is worth noting that the negative control, duloxetine, produced a number of significant abusespecific signals including drug dependence, drug diversion, intentional drug misuse, and intentional drug overdose. This is particularly important because there are only a few published reports of duloxetine misuse, all of which are cases of overdose (Scanlon et al., 2016), potentially indicating an under-recognized or under-studied area.

The current study has several limitations. FAERS has a low spontaneous reporting rate, containing an average of only $6 \%$ of all occurring drug-associated AEs (Hazell and Shakir, 2006). As a result, the incidence and prevalence of phenomena cannot be determined (de 
Table 4

Loglinear odds ratio estimates for the co-occurrence of a report of an abuse-specific adverse event and a possible indicator of abuse AE by drug.

\begin{tabular}{|c|c|c|c|}
\hline Interaction & $\begin{array}{l}\text { Gabapentin } \\
\text { OR }(95 \% \mathrm{CI})\end{array}$ & $\begin{array}{l}\text { Pregabalin } \\
\text { OR }(95 \% \mathrm{CI})\end{array}$ & Duloxetine \\
\hline AS-AE * Drug withdrawal syndrome & $6.55(5.24-8.19)$ & $3.08(2.44-3.87)$ & REF \\
\hline AS-AE * Euphoric mood & $5.45(2.70-12.26)$ & $2.47(1.27-5.42)$ & REF \\
\hline AS-AE * Auditory hallucination & $4.57(1.79-14.04)$ & $4.28(1.61-13.46)$ & REF \\
\hline AS-AE * Drug abuser & $3.01(1.26-7.82)$ & $2.45(0.81-7.78)$ & REF \\
\hline AS-AE * Ataxia & $2.85(1.26-7.68)$ & $1.34(0.55-3.79)$ & REF \\
\hline AS-AE * Delusion & $2.36(1.10-5.49)$ & $3.33(1.48-8.06)$ & REF \\
\hline AS-AE * Drug tolerance & $2.25(0.93-6.06)$ & $1.90(0.79-5.10)$ & REF \\
\hline AS-AE * Feeling drunk & $2.05(0.61-9.25)$ & $1.61(0.53-6.92)$ & REF \\
\hline AS-AE * Aggression & $1.98(1.35-2.92)$ & $2.47(1.68-3.66)$ & REF \\
\hline AS-AE * Psychotic disorder & $1.96(1.14-3.48)$ & $0.77(0.37-1.57)$ & REF \\
\hline AS-AE * Feeling of relaxation & $1.95(0.07-54.16)$ & $3.78(0.54-76.08)$ & REF \\
\hline AS-AE * Drug tolerance increased & $1.72(0.31-10.93)$ & $0.60(0.10-3.79)$ & REF \\
\hline AS-AE * Thinking abnormal & $1.52(0.96-2.47)$ & $1.03(0.61-1.73)$ & REF \\
\hline AS-AE * Mood altered & $1.37(0.75-2.57)$ & $1.47(0.80-2.74)$ & REF \\
\hline AS-AE * Feeling abnormal & $1.31(1.02-1.69)$ & $1.26(0.99-1.61)$ & REF \\
\hline AS-AE * Delirium & $1.24(0.76-2.10)$ & $0.64(0.35-1.16)$ & REF \\
\hline AS-AE * Somnolence & $1.24(0.99-1.55)$ & $0.91(0.73-1.14)$ & REF \\
\hline AS-AE * Confusional state & $1.20(0.94-1.55)$ & $0.82(0.62-1.08)$ & REF \\
\hline AS-AE * Dizziness & $1.19(0.94-1.50)$ & $1.05(0.83-1.32)$ & REF \\
\hline AS-AE * Visual hallucination & $1.16(0.50-2.92)$ & $1.29(0.54-3.29)$ & REF \\
\hline AS-AE * Mixed hallucinations & $1.15(0.24-6.16)$ & $2.90(0.82-13.63)$ & REF \\
\hline AS-AE * Hallucination & $1.08(0.74-1.58)$ & $0.90(0.60-1.36)$ & REF \\
\hline AS-AE * Disorientation & $1.02(0.63-1.67)$ & $0.93(0.56-1.55)$ & REF \\
\hline AS-AE * Fall & $0.94(0.73-1.22)$ & $0.90(0.68-1.19)$ & REF \\
\hline AS-AE * Off-label use & $0.93(0.70-1.22)$ & $1.46(1.11-1.92)$ & REF \\
\hline AS-AE * Incoherent & $0.90(0.37-2.32)$ & $0.47(0.15-1.41)$ & REF \\
\hline AS-AE * Gait disturbance & $0.73(0.51-1.05)$ & $0.82(0.58-1.18)$ & REF \\
\hline AS-AE * Elevated mood & - & $2.98(0.34-64.10)$ & REF \\
\hline AS-AE * Dissociation & - & $0.38(0.02-3.01)$ & REF \\
\hline
\end{tabular}

AE: adverse event; OR: odds ratio; $95 \%$ CI: $95 \%$ confidence interval; AS-AE: abuse-specific adverse event; REF: referent group.

Note: Missing results correspond to occasions where no events were reported.

Boldface indicates a significant result at $\mathrm{p}<.05$.

Boer, 2011; Rodriguez et al., 2001). However, the abuse signals detected herein provide a critical indication that further examination is required, especially in the context of a growing number of case reports of gabapentin misuse. Also, many external factors affect FAERS reporting such as the "notoriety effect" (Pariente et al., 2007), an uptick in reporting resulting from a safety alert, or the "ripple effect" where reporting is accelerated following notoriety of a drug in the same class (Pariente et al., 2007), among others (Hartnell and Wilson, 2004; Hochberg et al., 2009; Wang et al., 2010). By cumulating data over the 11 -year study period, we partially mitigated the impact of fluctuations present in the data. Importantly, some of the signals detected could have been confounded by the populations for which the drugs are prescribed (e.g., gabapentinoids prescribed off-label for mood disorders) as well as due to interactions with concomitant medications. However, the purpose of this study was not to assess cause-and-effect, but rather to corroborate described effects in case reports and provide hypotheses for future controlled clinical studies. Similarly, this study did not identify the primary suspect drug for each adverse event, which could provide further elucidation on the effects experienced; this is an important area for additional investigation.

\section{Conclusions}

We identified abuse-related signals for gabapentin and elucidated several CNS effects that may be associated with its abuse. Future studies, including large-scale controlled pharmacological studies are needed to determine whether the CNS effects are a direct result of gabapentin. Prescribers should be aware of gabapentin's abuse liability and effects that may accompany its misuse.

\section{Contributors}

Rachel Vickers-Smith

Jiangwen Sun

Richard J. Charnigo

Michelle R. Lofwall

Sharon L. Walsh

Jennifer R. Havens

\section{Role of funding source}

Nothing declared.

\section{Declaration of Competing Interest}

Drs. Vickers-Smith and Sun have no competing interests to declare. Dr. Charnigo has been a co-investigator on two grants from AstraZeneca. Dr. Lofwall has no competing interests related to gabapentinoids. She has received consulting fees from CVS Caremark, Braeburn Pharmaceuticals, Titan and Indivior, research funding from Braeburn Pharmaceuticals, and honorarium from PCM Scientific (PCM Scientific has received unrestricted educational grant funding from Reckitt Benckiser Pharmaceuticals). Dr. Walsh has received consulting fees from Lilly Inc., Summit Biosciences, Otsuka Pharmaceuticals, Trevi, and World Meds over the last two years and is receiving a gratis drug supply from Vanda Pharmaceuticals to support an NIH-funded project. Dr. Havens has received consulting fees from Pinney Associates and unrestricted research grant funding from Purdue Pharma.

\section{CRediT authorship contribution statement}

Rachel Vickers-Smith: Conceptualization, Methodology, Writing - 
original draft. Jiangwen Sun: Formal analysis, Writing - review \& editing, Visualization. Richard J. Charnigo: Methodology, Writing review \& editing. Michelle R. Lofwall: Conceptualization, Methodology, Writing - review \& editing. Sharon L. Walsh: Conceptualization, Methodology, Writing - review \& editing. Jennifer R.. Havens: Conceptualization, Writing - review \& editing.

\section{Acknowledgements}

This submission contains material that previously formed part of the first author's $\mathrm{PhD}$ dissertation, which was published in 2016 according to the University of Kentucky requirements.

\section{Appendix A. Supplementary data}

Supplementary material related to this article can be found, in the online version, at doi:https://doi.org/10.1016/j.drugalcdep.2019. 107709.

\section{References}

Ahmed, I., Poncet, A., 2016. PhViD: An R Package for Pharmacovigilance Signal Detection.

Baird, C.R., Fox, P., Colvin, L.A., 2014. Gabapentinoid abuse in order to potentiate the effect of methadone: a survey among substance misusers. Eur. Addict. Res. 20, 115-118. https://doi.org/10.1159/000355268.

Banda, J.M., Evans, L., Vanguri, R.S., Tatonetti, N.P., Ryan, P.B., Shah, N.H., 2016. A curated and standardized adverse drug event resource to accelerate drug safety research. Sci. Data 3, 160026. https://doi.org/10.1038/sdata.2016.26.

Bate, A., Lindquist, M., Edwards, I.R., Olsson, S., Orre, R., Lansner, A., De Freitas, R.M., 1998. A Bayesian neural network method for adverse drug reaction signal generation. Eur. J. Clin. Pharmacol. 54, 315-321.

Bisaga, A., Evans, S.M., 2006. The acute effects of gabapentin in combination with alcohol in heavy drinkers. Drug Alcohol Depend. 83, 25-32. https://doi.org/10.1016/j. drugalcdep.2005.10.008.

Bockbrader, H.N., Wesche, D., Miller, R., Chapel, S., Janiczek, N., Burger, P., 2010. A comparison of the pharmacokinetics and pharmacodynamics of pregabalin and gabapentin. Clin. Pharmacokinet. 49, 661-669. https://doi.org/10.2165/11536200000000000-00000.

Center for Drug Evaluation and Research, 2018a. Questions and Answers on FDA's Adverse Event Reporting System (FAERS) [WWW Document]. URL https://www. fda.gov/Drugs/GuidanceComplianceRegulatoryInformation/Surveillance/ AdverseDrugEffects/ (Accessed 2.22.19).

Center for Drug Evaluation and Research, 2018b. FDA Adverse Event Reporting System (FAERS) - FDA Adverse Event Reporting System (FAERS): Latest Quarterly Data Files [WWW Document]. URL https://www.fda.gov/Drugs/

GuidanceComplianceRegulatoryInformation/Surveillance/AdverseDrugEffects/ ucm082193.htm (Accessed 2.22.19).

Chiappini, S., Schifano, F., 2016. A decade of gabapentinoid misuse: an analysis of the European Medicines Agency's 'Suspected adverse drug reactions' database. CNS Drugs 30, 647-654. https://doi.org/10.1007/s40263-016-0359-y.

de Boer, A., 2011. When to publish measures of disproportionality derived from spontaneous reporting databases? Br. J. Clin. Pharmacol. 72, 909-911. https://doi.org/ 10.1111/j.1365-2125.2011.04087.x.

Diener, H.C., Dichgans, J., Bacher, M., Hülser, J., Liebich, H., 1983. Mechanisms of postural ataxia after intake of alcohol. Z. Rechtsmed. 90, 159-165.

Dowell, D., Haegerich, T.M., Chou, R., 2016. CDC Guideline for Prescribing Opioids for Chronic Pain - United States, 2016, MMWR: Recommendations and Reports. https:// doi.org/10.15585/mmwr.rr6501e1.

European Medicines Agency, 2006. Guideline on the Use of Statistical Signal Detection Methods in the EudraVigilance Data Analysis System.

European Monitoring Centre for Drugs and Drug Addiction, 2012. EMCDDA-Europol 2012 Annual Report on the Implementation of Council Decision 2005/387/JHA https://doi.org/10.2810/99367.

Evans, S.J.W., Waller, P.C., Davis, S., 2001. Use of proportional reporting ratios (PRRs) for signal generation from spontaneous adverse drug reaction reports. Pharmacoepidemiol. Drug Saf. 10, 483-486. https://doi.org/10.1002/pds.677.

Fischer, J.H., Barr, A.N., Rogers, S.L., Fischer, P.A., Trudeau, V.L., 1994. Lack of serious toxicity following gabapentin overdose. Neurology 44, 982-983.

Hamer, A.M., Haxby, D.G., McFarland, B.H., Ketchum, K., 2002. Gabapentin use in a managed medicaid population. J. Manag. Care Pharm. 8, 266-271.

Hartnell, N.R., Wilson, J.P., 2004. Replication of the weber effect using postmarketing adverse event reports voluntarily submitted to the united states food and drug administration. Pharmacotherapy 24, 743-749. https://doi.org/10.1592/phco.24.8. 743.36068.

Hazell, L., Shakir, S.A.W., 2006. Under-reporting of adverse drug reactions. Drug Saf. 29, 385-396. https://doi.org/10.2165/00002018-200629050-00003.

Hochberg, A.M., Hauben, M., Pearson, R.K., O’Hara, D.J., Reisinger, S.J., 2009. Systematic investigation of time windows for adverse event data mining for recently approved drugs. J. Clin. Pharmacol. 49, 626-633. https://doi.org/10.1177/ 0091270009333484

Kapil, V., Green, J.L., Le Lait, M.C., Wood, D.M., Dargan, P.I., 2014. Misuse of the gammaaminobutyric acid analogues baclofen, gabapentin and pregabalin in the UK. Br. J. Clin. Pharmacol. 78, 190-191.

Moore, N., Kreft-Jais, C., Haramburu, F., Noblet, C., Andrejak, M., Ollagnier, M., Bégaud, B., 1997. Reports of hypoglycaemia associated with the use of ACE inhibitors and other drugs: a case/non-case study in the French pharmacovigilance system database. Br. J. Clin. Pharmacol. 44, 513-518.

Howard II, J.P., 2018. Phonetic algorithms in R. J. Open Source Softw. 3, 480. https:// doi.org/10.21105/joss.00480.

Pariente, A., Gregoire, F., Fourrier-Reglat, A., Haramburu, F., Moore, N., 2007. Impact of safety alerts on measures of disproportionality in spontaneous reporting databases. Drug Saf. 30, 891-898. https://doi.org/10.2165/00002018-200730100-00007.

Peterson, B.L., 2009. Prevalence of gabapentin in impaired driving cases in Washington State in 2003-2007. J. Anal. Toxicol. 33, 545-549.

Poluzzi, E., Raschi, E., Piccinni, C., De, F., 2012. Data mining techniques in pharmacovigilance: analysis of the publicly accessible FDA adverse event reporting system (AERS). Data Mining Applications in Engineering and Medicine. InTech.https://doi. org $/ 10.5772 / 50095$.

Radley, D.C., Finkelstein, S.N., Stafford, R.S., 2006. Off-label prescribing among officebased physicians. Arch. Intern. Med. 166, 1021-1026. https://doi.org/10.1001/ archinte.166.9.1021.

Reeves, R.R., Burke, R.S., 2014. Abuse of combinations of gabapentin and quetiapine. Prim. Care Companion CNS Disord. 16, 16. https://doi.org/10.4088/PCC.14101660.

Reeves, R.R., Ladner, M.E., 2014. Potentiation of the effect of buprenorphine/naloxone with gabapentin or quetiapine. Am. J. Psychiatry. https://doi.org/10.1176/appi.ajp. 2014.13111526.

Rodriguez, E.M., Staffa, J.A., Graham, D.J., 2001. The role of databases in drug postmarketing surveillance. Pharmacoepidemiol. Drug Saf. 10, 407-410. https://doi.org/ 10.1002/pds.615.

Roehrs, T., Roth, T., 2001. Sleep, sleepiness, sleep disorders and alcohol use and abuse. Sleep Med. Rev. 5, 287-297. https://doi.org/10.1053/smrv.2001.0162.

Satish, R., Kandasamy, A., Jayarajan, D., Benegal, V., 2015. Gabapentin dependence in a patient with opioid dependence syndrome. J. Neuropsychiatry Clin. Neurosci. 27, e64. https://doi.org/10.1176/appi.neuropsych.13110339.

Scanlon, K.A., Stoppacher, R., Blum, L.M., Starkey, S.J., 2016. Comprehensive duloxetine analysis in a fatal overdose. J. Anal. Toxicol. 40, 167-170. https://doi.org/10.1093/ jat/bkv134.

Schifano, F., D’Offizi, S., Piccione, M., Corazza, O., Deluca, P., Davey, Z., Di Melchiorre, G., Di Furia, L., Farre, M., Flesland, L., Mannonen, M., Majava, A., Pagani, S., Peltoniemi, T., Siemann, H., Skutle, A., Torrens, M., Pezzolesi, C., van der Kreeft, P., Scherbaum, N., 2011. Is there a recreational misuse potential for pregabalin? Analysis of anecdotal online reports in comparison with related gabapentin and clonazepam data. Psychother. Psychosom. 80, 118-122. https://doi.org/10.1159/000321079.

Schwan, S., Sundström, A., Stjernberg, E., Hallberg, E., Hallberg, P., 2010. A signal for an abuse liability for pregabalin-results from the Swedish spontaneous adverse drug reaction reporting system. Eur. J. Clin. Pharmacol. 66, 947-953. https://doi.org/10. 1007/s00228-010-0853-y.

Smith, S.M., Dart, R.C., Katz, N.P., Paillard, F., Adams, E.H., Comer, S.D., Degroot, A., Edwards, R.R., Haddox, D.J., Jaffe, J.H., Jones, C.M., Kleber, H.D., Kopecky, E.A., Markman, J.D., Montoya, I.D., O'Brien, C., Roland, C.L., Stanton, M., Strain, E.C., Vorsanger, G., Wasan, A.D., Weiss, R.D., Turk, D.C., Dworkin, R.H., Analgesic, Anesthetic, Addiction Clinical Trials, Translations, Innovations, Opportunities, and Networks (ACTTION) public-private partnership, 2013. Classification and definition of misuse, abuse, and related events in clinical trials: ACTTION systematic review and recommendations. Pain 154, 2287-2296. https://doi.org/10.1016/j.pain.2013.05. 053.

Smith, R.V., Havens, J.R., Walsh, S.L., 2016. Gabapentin misuse, abuse and diversion: a systematic review. Addiction 111, 1160-1174. https://doi.org/10.1111/add.13324.

Smith, R.V., Lofwall, M.R., Havens, J.R., 2015. Abuse and diversion of gabapentin among nonmedical prescription opioid users in Appalachian Kentucky. Am. J. Psychiatry 172, 487-488. https://doi.org/10.1176/appi.ajp.2014.14101272.

Szarfman, A., Machado, S.G., O'Neill, R.T., 2002. Use of screening algorithms and computer systems to efficiently signal higher-than-expected combinations of drugs and events in the US FDA's spontaneous reports database. Drug Saf. 25, 381-392. https:// doi.org/10.2165/00002018-200225060-00001.

U.S. Department of Justice Drug Enforcement Administration Diversion Control Division, 2005. 2005 - Placement of Pregabalin Into Schedule V [WWW Document]. URL https://www.deadiversion.usdoj.gov/fed_regs/rules/2005/fr0728.htm (Accessed 2.23.19).

U.S. Food and Drug Administration, 2016. Center for Drug Evaluation and Research 20152016 Drug Safety Priorities: Initiatives and Innovation.

U.S. Food and Drug Administration, 2005. Lyrica (Pregabalin) Capsules Drug Approval Package [WWW Document]. URL https://www.accessdata.fda.gov/drugsatfda docs/nda/2004/021446 LyricaTOC.cfm (Accessed 2.22.19).

van Puijenbroek, E.P., Bate, A., Leufkens, H.G.M., Lindquist, M., Orre, R., Egberts, A.C.G., 2002. A comparison of measures of disproportionality for signal detection in spontaneous reporting systems for adverse drug reactions. Pharmacoepidemiol. Drug Saf. 11, 3-10. https://doi.org/10.1002/pds.668.

Vickers Smith, R., Boland, E.M., Young, A.M., Lofwall, M.R., Quiroz, A., Staton, M., Havens, J.R., 2018. A qualitative analysis of gabapentin misuse and diversion among people who use drugs in Appalachian Kentucky. Psychol. Addict. Behav. 32. https:// doi.org/10.1037/adb0000337.

Wang, H., Hochberg, A.M., Pearson, R.K., Hauben, M., 2010. An Experimental Investigation of Masking in the US FDA Adverse Event Reporting System Database. 
Drug Saf. 33, 1117-1133. https://doi.org/10.2165/11584390-000000000-00000.

Wilens, T., Zulauf, C., Ryland, D., Carrellas, N., Catalina-Wellington, I., 2015. Prescription medication misuse among opioid dependent patients seeking inpatient detoxification. Am. J. Addict. 24, 173-177. https://doi.org/10.1111/ajad.12159.

World Health Organization, 2015a. Lexicon of Alcohol and Drug Terms Published by the World Health Organization [WWW Document], URL. http://www.who.int/ substance_abuse/terminology/who_lexicon/en/.
World Health Organization, 2015b. WHO | Pharmacovigilance [WWW Document]. WHO. URL https://www.who.int/medicines/areas/quality safety/safety_efficacy/ pharmvigi/en/ (Accessed 2.22.19)

World Health Organization, 2012. Safety Monitoring of Medicinal Products.

Zhang, M., Sproule, B., 2015. Problematic pregabalin and gabapentin use: results from the canada vigilance adverse reaction online database. Drug Alcohol Depend. 156, e244. https://doi.org/10.1016/J.DRUGALCDEP.2015.07.657. 